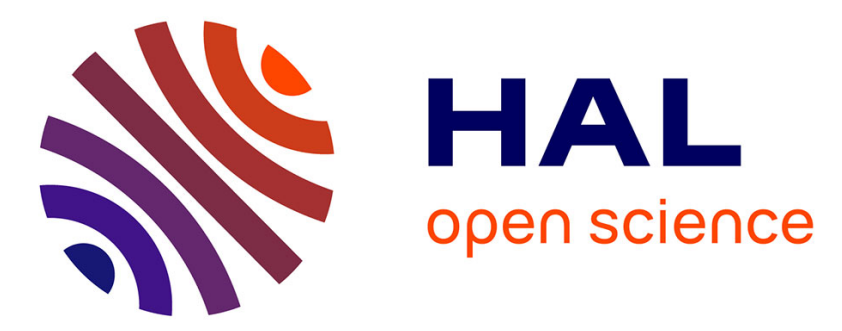

\title{
Cardiac surgery and repair of pectus deformities: When and how?
}

Ilir Hysi, André Vincentelli, Francis Juthier, Lotfi Benhamed, Carlo Banfi, Natacha Rousse, Jean-Marc Frapier, Fabien Doguet, Alain Prat, Alain Wurtz

\section{- To cite this version:}

Ilir Hysi, André Vincentelli, Francis Juthier, Lotfi Benhamed, Carlo Banfi, et al.. Cardiac surgery and repair of pectus deformities: When and how?. International Journal of Cardiology, 2015, 194, pp.83 86. 10.1016/j.ijcard.2015.05.100 . hal-01768260

\section{HAL Id: hal-01768260 \\ https://hal.umontpellier.fr/hal-01768260}

Submitted on 6 Nov 2018

HAL is a multi-disciplinary open access archive for the deposit and dissemination of scientific research documents, whether they are published or not. The documents may come from teaching and research institutions in France or abroad, or from public or private research centers.
L'archive ouverte pluridisciplinaire HAL, est destinée au dépôt et à la diffusion de documents scientifiques de niveau recherche, publiés ou non, émanant des établissements d'enseignement et de recherche français ou étrangers, des laboratoires publics ou privés. 


\title{
Cardiac surgery and repair of pectus deformities: When and how? is $^{\text {is }}$
}

\author{
Ilir Hysi ${ }^{\mathrm{a}, *}$, André Vincentelli ${ }^{\mathrm{a}}$, Francis Juthier ${ }^{\mathrm{a}}$, Lotfi Benhamed ${ }^{\mathrm{b}}$, Carlo Banfi ${ }^{\mathrm{a}}$, Natacha Rousse ${ }^{\mathrm{a}}$, \\ Jean-Marc Frapier ${ }^{c}$, Fabien Doguet ${ }^{\mathrm{d}}$, Alain Prat ${ }^{\mathrm{a}}$, Alain Wurtz ${ }^{\mathrm{a}}$ \\ a Cardiac and Thoracic Surgery Division, Lille University Teaching Hospital, CHU Lille, Lille, France \\ ${ }^{\mathrm{b}}$ Department of Thoracic Surgery, Valenciennes Hospital, Valenciennes, France \\ c Department of Cardiac Surgery, Arnaud de Villeneuve University Hospital, Montpellier, France \\ ${ }^{d}$ Department of Thoracic and Cardiovascular Surgery, Rouen University Hospital, Rouen, France
}

Keywords:

Cardiac surgery

Cardiopulmonary bypass

Pectus deformities

\begin{abstract}
A B S T R A C T
Objectives: There is currently a lack of recommendations about patients with pectus deformities requiring cardiac surgery. This study reports the results of our surgical strategy on this issue.

Methods: Eleven patients, from three centers treated over a 9-year period were included in this study. Pectus deformities were operated with a modified Ravitch procedure. In the case of pectus excavatum repair and concomitant cardiac surgery, subperichondrial resection of abnormal rib cartilages was always performed before the sternotomy and an easily removable retrosternal metallic strut was inserted at the end of the procedure ensuring anterior chest wall stability. During follow-up patients had to estimate their current appearance with a numeric scale ranging from 0 to 100 .

Results: Mean age was $27 \pm 9.4$ years. Pectus excavatum was present in 8 patients and pectus arcuatum in 3 . There were 6 Marfan syndrome patients. Nine patients had concomitant surgery and, 2 underwent pectus repair after a history of cardiac surgery. There was no operative mortality. In the case of concomitant surgery, heart exposure through median sternotomy was facilitated by abnormal rib cartilage resection. Median follow-up was 54 months (range 16.7-119.7). Mean cosmetic result evaluated by the patients was $97.3( \pm 2.5)$.

Conclusions: In adults, concomitant scheduled surgery is reliable and offers excellent long-term cosmetic results. Moreover, it allows a better thoracic exposition with no added perioperative risk. The modified Ravitch technique seems more adequate in these patients as it can be used in all types of pectus deformities.
\end{abstract}

\section{Introduction}

Anterior chest wall deformities are not uncommon. They consist of pectus excavatum (PEx), the most frequent form of chest deformities, and by protrusion deformities such as pectus arcuatum or carinatum. Pectus deformities are usually isolated and patients are referred for scheduled surgical correction. However, some patients present with coexisting pectus deformities and congenital or acquired cardiac disease requiring surgical correction. Traditionally, the combined approach has been avoided due to the bleeding risk or other major complications such as infection or sternal dehiscence [1]. Growing evidences recently appear to both feasibility and reliability of the simultaneous surgical correction, especially in patients with connective tissue disorders such

\footnotetext{
is "All authors take responsibility for all aspects of the reliability and freedom from bias of the data presented and their discussed interpretation".

* Corresponding author at: Clinique de Chirurgie Cardiaque et Thoracique, CHU de Lille, F59037 Lille Cedex, France.

E-mail address: ilirhysi@gmail.com (I. Hysi).
}

as Marfan or Ehlers-Danlos syndromes [2-4]. However important questions remain unanswered, notably: (i) on the effect of age; (ii) safety of concomitant surgery; and (iii) choice of procedure, Ravitch, Nuss or other techniques.

\section{Materials and methods}

\subsection{Population}

This was a retrospective study of 11 patients from 3 centers (Lille, Montpellier, Rouen) who have received treatment over a 9-year period (2005-2014). Of these patients, 2 have been previously reported [2]. Nine patients underwent concomitant surgery and 2 patients with a medical history of cardiac surgery underwent a delayed pectus repair. Transthoracic echocardiograms were performed in all patients, specifically looking for patent foramen ovale in the cases of PEx. Patients' clinical and biological data were collected from medical charts. The study was approved by the Institutional Review Board of the French Society 
of Thoracic and Cardio-Vascular Surgery (CERC-SFCTCV-2014-3-1-1821-28-Hyll) and patients' consents were orally obtained.

\subsection{Surgical technique}

The pectus repair was performed by using a simplified open procedure based on the subperichondrial resection of abnormal rib cartilages and optional transverse osteotomy across the anterior table of the upper sternum, as previously described [5]. Depending on the morphology of pectus deformity, resection was performed at the level of the second/ third, to the seventh paired rib cartilages for PEx correction, and second to fourth/fifth for pectus arcuatum.

In the case of concomitant surgery, patients were monitored in the operating room as in all routine cardiac surgical procedures. Patients with PEx, were operated with a sequential technique as described elsewhere [2]. Briefly, after a vertical presternal incision and minimal detachment of the pectoralis major and rectus abdominis muscles, the subperichondrial resection of the lower paired rib cartilages was performed. Sternotomy and cardiac procedure with cardiopulmonary bypass, according to surgeon's preferences, were then carried out. Last, after heparin reversal and sternum closure with six to eight simple wires, PEx repair was achieved by additional resection of the upper second and third cartilages, sternal osteotomy if needed and placement of a substernal metallic strut (Medicalex, Bagneux, France). The latter was positioned at the level of the sixth perichondrial sheaths and anterior to the ribs laterally and secured to the sternum with an absorbable suture [2]. In the case of pectus arcuatum, the pectus repair was performed immediately after the achievement of the cardiac procedure, without insertion of a metallic strut. Surgical chest tubes were placed in the pericardium, mediastinum and presternal space. Antibiotic coverage was administered as usually in cardiac surgery, without any modification due to the presence of the metallic strut.

\subsection{Postoperative management}

After the surgical procedure, patients were monitored in intensive care units (ICU) for at least $48 \mathrm{~h}$. Total amount of fluid drainage within the first $24 \mathrm{~h}$ was assessed.

\subsection{Follow-up}

Follow-up was complete. The metallic strut was routinely removed under outpatient local anesthesia procedure, 5-9 months after the initial operation. The most recent clinical data were collected by telephone interviews. Patients were asked to estimate their current cosmetic appearance with a numeric scale ranging from 0 (the lowest) to 100 (the highest).

\section{Results}

\subsection{Patient demographics}

Mean age of our cohort was $27( \pm 9.4)$ years and were mostly male $(\mathrm{N}=9$ or $81.8 \%$ ). Pectus excavatum and arcuatum were present in 8 (72.7\%) and 3 (27.3\%) patients, respectively. In patients with PEx and pectus arcuatum, the mean Haller index was $5.06( \pm 1.73)$ and 2.5 $( \pm 0.8)$, respectively (Table 1$)$. Nine patients $(81.8 \%)$ underwent concomitant surgery, and 2 patients with a history of cardiac surgery (atrial septal defect in patient 3 and transposition of the great vessels in patient 7) underwent a delayed pectus repair (pectus arcuatum and PEx, respectively). Table 1 summarizes surgical details for all patients of our cohort. Five patients (3, 6-9), had a previous sternotomy, due to a history of cardiac surgery during childhood or infancy. Patient 8 presented with 4 previous sternotomies. He had two recurrent ventricular septal defect closure, and pulmonary and aortic stenosis correction. Routine preoperative transthoracic echocardiograms showed a patent foramen ovale in 2 patients ( 7 and 9). There were 6 (54.5\%) Marfan patients requiring an aortic root surgery and 2 of them (patients 2 and 10) underwent an additional aortic arch replacement.

\subsection{Operative characteristics and postoperative outcomes}

In patients who underwent concomitant surgery, mean cross-clamp, CPB and pectus operative times were $109.9( \pm 55.4)$ min, $183.4( \pm 87.2)$ min and $167( \pm 29.9)$ min respectively. After sternal closure with wires, partial sternal transversal osteotomy was carried out in 5 patients. Total amount of fluid drainage in the first $24 \mathrm{~h}$ was $736( \pm 354) \mathrm{ml}$. Average length of ICU and hospital stays were $6.1( \pm 8.8)$ days and $19.3( \pm 14.1)$ days, respectively. In both patients ( 3 and 7 ) who underwent a delayed pectus repair operative times were 117 and $120 \mathrm{~min}$, total amount of fluid drainage in the first $24 \mathrm{~h}$ was 100 and $150 \mathrm{ml}$ and they were discharged on days 4 and 8 , respectively.

For the whole cohort, there was no operative mortality and overall morbidity was of $63.6 \%(n=7)$. In these patients morbidity details were as follows: 3 lymphatic subcutaneous effusions, 3 unilateral lung infections and 1 stroke with complete recovery. In all our patients, we did not observe any injury of the internal thoracic arteries and sternal healing occurred as usually after cardiac surgery within six to ten weeks after the procedure. When a metallic strut was inserted, median removal delay was 6.2 months (range 5.5-8.9). Median follow-up was of 54 months (range 16.7-119.7) and mean cosmetic result of the pectus repair, evaluated by the patients, was $97.3( \pm 2.5)$.

\section{Discussion}

Cardiac surgery indication in patients suffering from pectus deformities is infrequent [1]. Indication and timing of concomitant surgery

Table 1

Demographics, clinical and operative characteristics.

\begin{tabular}{|c|c|c|c|c|c|c|c|c|c|}
\hline Patient no. & Age & Sex & $\begin{array}{l}\text { Pectus } \\
\text { deformity }\end{array}$ & $\begin{array}{l}\text { Haller } \\
\text { index }\end{array}$ & Marfan & Previous cardiotomy & $\begin{array}{l}\text { Concomitant } \\
\text { surgery }\end{array}$ & $\begin{array}{l}\text { Cardiac } \\
\text { procedure }\end{array}$ & $\begin{array}{l}\text { Follow-up after pectus repair } \\
\text { (months) }\end{array}$ \\
\hline 1 & 14 & $\mathrm{~F}$ & PEx & 7.1 & + & - & + & T David & 119 \\
\hline 2 & 37 & M & PEX & 5.9 & + & - & + & T David + Arch & 98 \\
\hline 3 & 22 & M & PA & 2.6 & - & ASD & - & - & 59 \\
\hline 4 & 23 & M & PEx & 2.9 & - & - & + & Cor triatriatum & 55 \\
\hline 5 & 29 & M & PA & 2.4 & - & TOF & + & RVOTR & 55 \\
\hline 6 & 24 & M & PEx & 2.9 & - & TOF & + & RVOTR & 54 \\
\hline 7 & 17 & M & PEx & 5.4 & + & Transposition of great vessels & - & - & 53 \\
\hline 8 & 36 & M & PA & 2.5 & - & 4 & + & Bentall & 46 \\
\hline 9 & 28 & $\mathrm{~F}$ & PEx & 3.7 & + & - & + & T David & 43 \\
\hline 10 & 48 & M & PEx & 6.8 & + & - & + & T David + Arch & 32 \\
\hline 11 & 35 & M & PEx & 3.4 & + & - & + & T David & 16 \\
\hline
\end{tabular}

M: Male; F: female; PEx: pectus excavatum; PA: pectus arcuatum; ASD: atrial septal defect; TOF: Tetralogy of Fallot; RVOTR: right ventricle outflow tract reconstruction. 
remain to be defined. Some authors advocate simultaneous repair $[4,6]$, while others debate the blanket application of this strategy, because of concerns about potential major complications such as bleeding, prolonged operation times, postoperative instability of the chest wall and infection due to the metallic bar [1,7].

Pectus excavatum when diagnosed during the first year or during the childhood has respectively a $50 \%$ or $15 \%$ rate of deformity disappearance or improvement as shown by Humphreys and Jaretzki [8]. In addition, early surgical chest wall repair bears the increased risk of latter recurrence [9] or occasionally restrictive chest wall deformity [10]. Last, the current orthopedic treatments are very efficient in this patients' population [5]. On the basis of the above, we believe that concomitant surgery in infants and children may be better avoided and, if needed, pectus repair be delayed until the end of the second growth spurt.

In young patients with full body growth as well as adults with pectus deformities and congenital or acquired cardiomyopathies, the surgical strategy may differ. In this case no spontaneous improvement is expected [8] and concomitant cardiac surgery and pectus repair may be recommended. Concomitant surgery requires optimal operative exposure during cardiac procedure without any added bleeding risk. An optimal chest-wall stabilization in the postoperative period is also mandatory, usually by means of a device that enables eventual urgent postoperative reentry and cardiac resuscitation maneuvers [2]. Several authors have followed this approach with good postoperative results in coronary artery bypass grafting [11], aortic root surgery [12] and acute type A aortic dissection [13]. In addition, concomitant pectus repair may be recommended as it improves cardiovascular function by facilitating heart filling [14] and potentially improves postoperative outcome.

Our results support that the modified sequential Ravitch approach [2] is reliable and is not associated with major morbidity. Our Ravitchtype repair allowed treatment of all types of chest wall deformities with acceptable degrees of postoperative bleeding due to careful preservation of the pericondrial sheets, which protects the intercostal and internal thoracic arteries from damage. Moreover, the subperichondrial excision of the costal cartilages decreased the traction forces on the sternum resulting in a low postoperative risk of sternal dehiscence.

With respect to the surgical strategy, different techniques have been suggested for the PEx correction. Hasegawa and colleagues [6] proposed an initial subperichondrial resection of the deformed costal cartilages followed by section of the deformed sternum in 2-3 points and then fixation of the sternum in elevated position using two Kirschner wires and a bridge external traction. They concluded that this technique permitted satisfactory simultaneous treatment of congenital heart disease and PEx deformities. However, as the Kirschner wires may present frequent displacements and the external traction seriously limits patient's recovery in the postoperative period, this technique may be inadequate for concomitant surgery. Subsequently, Okamura and colleagues [15] proposed the use of convex Nuss bars in concomitant surgery. Since, others have expressed the potential interest of the Nuss technique in this indication $[3,16]$. However, the Nuss repair raises several issues. First, the curved bar used for chest wall stabilization impedes effective external cardiac compression during an eventual postoperative external cardiac massage [17] or prompt reentry. Second, the Nuss procedure presents, in the setting of concomitant surgery via a mid sternotomy, a risk of sternal dehiscence from the pushing forces of the elastic bar to the anterior chest wall [18]. Third, Bouchard and colleagues [18] have shown that postoperative pericardial effusions following the Nuss procedure could lead to dense adhesions between the curved bar, the pericardium and the underlying heart, thus, increasing the risk of heart injury during the bar removal. Fourth, a history of cardiac surgery also strongly contraindicates the Nuss, because of pericardial/ myocardial adhesions the bar placement or removal is becoming a high risk procedure [19]. It has also been shown that the Nuss bar negatively affects the blood flow in the internal thoracic arteries with almost $45 \%$ of the patients having artery obstruction or severe reduced blood flow in the postoperative period, and 67\% after Nuss bar removal $[20,21]$. Since the internal thoracic arteries are widely used for coronary bypass grafting, these findings raise an issue for the surgical treatment of coronary disease. Finally, in elderly patients with acquired cardiomyopathies and pectus deformities the chest wall may be very rigid and might contraindicate the Nuss procedure.

For all the reasons above-mentioned the Nuss procedure may be unsuitable for concomitant or delayed cardiac surgery and pectus repair. A synthetic algorithm of our operative strategy is proposed in Fig. 1.

In conclusion, concomitant surgery is contraindicated before adolescence because pectus deformity may spontaneously disappear or recur after early sternal surgery. Alternatively, concomitant surgery is a reliable strategy in adolescents and adults, offering excellent longterm results. With respect to the pectus repair technique, the modified Ravitch technique may be more adequate as it can be used in all types of deformities and in concomitant surgery. It also provides optimal operative exposure during cardiac procedure, and allows easy postoperative reentry and resuscitation maneuvers if needed.

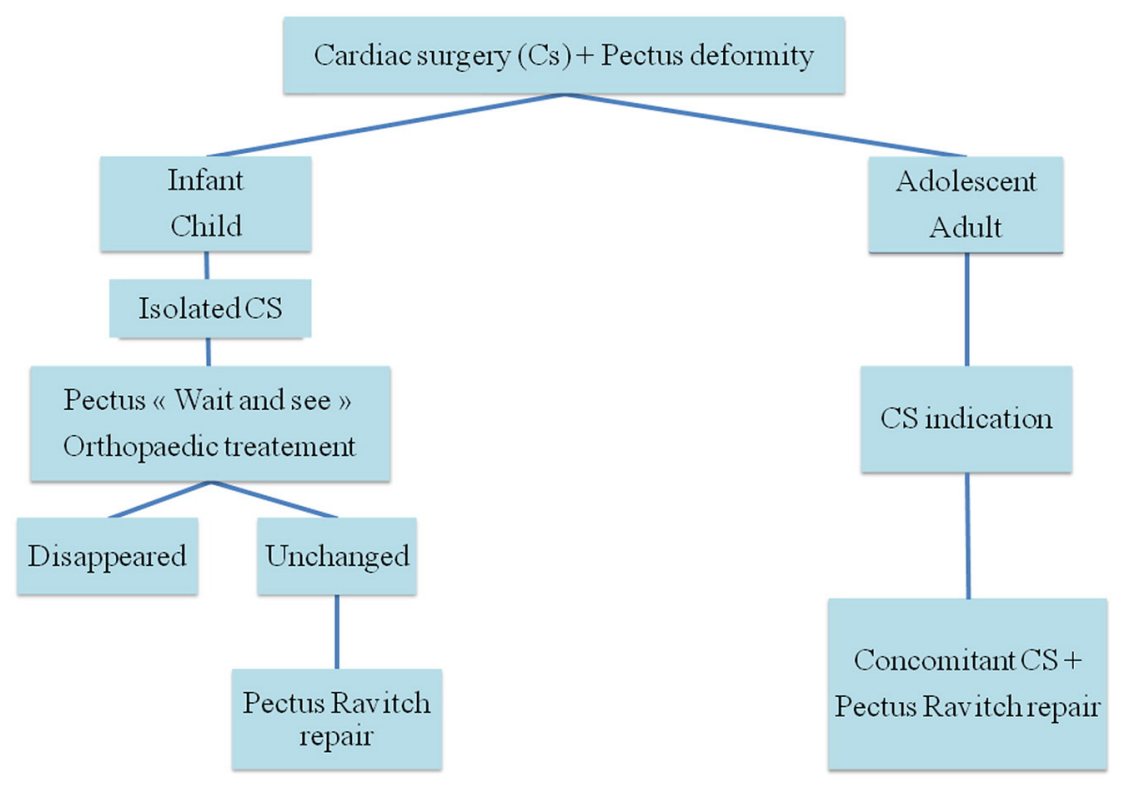

Fig. 1. Algorithm of our surgical strategy for concomitant cardiomyopathy and pectus deformity. 


\section{Conflict of interest}

The authors report no relationships that could be construed as a conflict of interest.

\section{References}

[1] R.C. Shamberger, K.J. Welch, A.R. Castaneda, J.F. Keane, D.C. Fyler, Anterior chest wall deformities and congenital heart disease, J. Thorac. Cardiovasc. Surg. 96 (1988) 427-432.

[2] N. Rousse, F. Juthier, A. Prat, A. Wurtz, Staged repair of pectus excavatum during an aortic valve-sparing operation, J. Thorac. Cardiovasc. Surg. 141 (2011) e28-e30.

[3] M.G. Sacco Casamassima, L.L. Wong, D. Papandria, et al., Modified Nuss procedure in concurrent repair of pectus excavatum and open heart surgery, Ann. Thorac. Surg. 95 (2013) 1043-1049.

[4] J. Schmidt, B. Redwan, V. Koesek, et al., Pectus excavatum and cardiac surgery: simultaneous correction advocated, Thorac. Cardiovasc. Surg. 62 (2014) 238-244.

[5] A. Wurtz, N. Rousse, L. Benhamed, et al., Simplified open repair for anterior chest wall deformities. Analysis of results in 205 patients, Orthop. Traumatol. Surg. Res. 98 (2012) 319-326.

[6] T. Hasegawa, M. Yamaguchi, Y. Ohshima, N. Yoshimura, S. Oka, Y. Ootaki, Simultaneous repair of pectus excavatum and congenital heart disease over the past 30 years, Eur. J. Cardiothorac. Surg. 22 (2002) 874-878.

[7] W.G. Jones, L. Hoffman, R.B. Devereux, O.W. Isom, J.P. Gold, Staged approach to combined repair of pectus excavatum and lesions of the heart, Ann. Thorac. Surg. 57 (1994) 212-214.

[8] G.H. Humphreys II, A. Jaretzki III, Pectus excavatum. Late results with and without operation, J. Thorac. Cardiovasc. Surg. 80 (1980) 686-695.

[9] C. Haller, K. Sarai, M. Siepe, F. Beyersdorf, Concomitant mitral valve replacement and re-re-repair of severe pectus deformity correction in a patient with Marfan syndrome, J. Thorac. Cardiovasc. Surg. 140 (2010) e75-e76.

[10] D.E. Jaroszewski, D.M. Notrica, L.E. McMahon, et al., Operative management of acquired thoracic dystrophy in adults after open pectus excavatum repair, Ann. Thorac. Surg. 97 (2014) 1764-1770.
[11] D. Pevni, O. Lev-Ran, I. Shapira, R. Mohr, Combined repair of pectus excavatum and coronary artery bypass grafting, Eur. J. Cardiothorac. Surg. 17 (2000) 495-497.

[12] K.C. Javangula, T.J.P. Batchelor, O. Jaber, K.G. Watterson, K. Papagiannopoulos, Combined severe pectus excavatum correction and aortic root replacement in Marfan's syndrome, Ann. Thorac. Surg. 81 (2006) 1913-1915.

[13] S. Schwill, K. Kallenbach, C.J. Beller, M. Karck, An alternative surgical approach for the combined treatment of pectus excavatum and acute aortic dissection type-A in Marfan syndrome, Interact. Cardiovasc. Thorac. Surg. 12 (2011) 526-528.

[14] R. Neviere, L. Benhamed, A. Duva Pentiah, A. Wurtz, Pectus excavatum repair improves respiratory pump efficacy and cardiovascular function at exercise, J. Thorac. Cardiovasc. Surg. 145 (2013) 605-606.

[15] T. Okamura, Y. Nagase, F. Mitsui, M. Shibairi, K. Utsumi, H. Watanabe, Simultaneous repair of pectus excavatum and congenital heart defect in adults by using the convex bar, Ann. Thorac. Surg. 77 (2004) 1827-1829.

[16] G.K. Zoeller, G.S. Zallen, P.L. Glick, Cardiopulmonary resuscitation in patients with Nuss bar-a case report and review of the literature, J. Pediatr. Surg. 40 (2005) 1788-1791.

[17] T. Okay, B. Ketenci, O.U. Imamoglu, et al., Simultaneous open-heart surgery and pectus deformity correction, Surg. Today 38 (2008) 592-596.

[18] S. Bouchard, A.R. Hong, B.F. Gilchrist, K.A. Kuenzler, Catastrophic cardiac injuries encountered during the minimally invasive repair of pectus excavatum, Semin. Pediatr. Surg. 18 (2009) 66-72.

[19] F.-M. Haecker, T. Berberich, J. Mayr, F. Gambazzi, Near-fatal bleeding after transmyocardial ventricle lesion during removal of the pectus bar after the Nuss procedure, J. Thorac. Cardiovasc. Surg. 138 (2009) 1240-1241.

[20] M. Yüksel, M.H. Özalper, K. Bostanci, et al., Do Nuss bars compromise the blood flow of the internal mammary arteries? Interact. Cardiovasc. Thorac. Surg. 17 (2013) 571-575.

[21] K. Külcü, T.W. Elenbaas, D.T. Nguyen, et al., Patency of the internal mammary arteries after removal of the Nuss bar: an initial report, Interact. Cardiovasc. Thorac. Surg. 19 (2014) 6-9. 